\title{
Pattern of Diabetic Eye Diseases in a Tertiary Health Facility, South East Nigeria
}

\author{
Nkpozi MO, ${ }^{1}$ Adukwu BU, ${ }^{2}$ Ugwu ET. ${ }^{3}$
}

${ }^{\prime}$ Department of Internal Medicine, Abia State University Teaching Hospital, ABSUTH, Aba, Nigeria.

${ }^{2}$ Department of Ophthalmology, ABSUTH, Aba, Nigeria.

${ }^{3}$ Department of Internal Medicine, Enugu State University Teaching Hospital (ESUTH), Enugu, Nigeria.

*Corresponding Author: Dr M.O. Nkpozi, Endocrinology, Diabetes and Metabolism Unit, Department of Internal Medicine, Abia State University Teaching Hospital, ABSUTH, Aba, Nigeria. Mobile phone: +2348058525899. Email: $\underline{\text { marcelnkpozi@gmail.com }}$

\begin{abstract}
Date Accepted: $09 / 02 / 2020$

Date Published: 03/04/2020

Diabetes mellitus (DM) is characterized by chronic hyperglycaemia; the latter predisposes persons living with diabetes to certain diseases of the eyes such as diabetic retinopathy, diabetic macular oedema, cataract, glaucoma etc, each of which may progress to visual loss and blindness. The burden and pattern of diabetic eye diseases among persons living with diabetes in the commercial city of Aba, Nigeria is not known. This study, therefore, set out to determine this. This was a 6-year retrospective study in which all diabetic patients referred to or presenting at the Ophthalmology clinic of Abia State University Teaching Hospital (ABSUTH) Aba, Nigeria between January 2013 and December 2018 were included. The patients were examined by ophthalmologists and optometrists. Visual acuity, refraction, tonometry, slitlamp examination of the anterior segment and fundus examination were carried out on each patient. Data was analyzed using SPSS version 20.0 and $\mathrm{p}<0.05$ was considered statistically significant. Participants in the study were 56 (44.4\%) males and 70 (55.6\%) females. Diabetic ocular complications occurred in $2.4 \%$ of the total Ophthalmology clinic visits in ABSUTH, Aba. The commonest diabetic eye disease was cataract which was present in $50 \%$ of the participants, No diabetic patient presented with blindness and the commonest co morbid disease in the participants was systemic hypertension. Ocular complications of DM constitute a significant burden to the Ophthalmology clinic visits in the commercial city of Aba and the commonest of these complications is cataract.
\end{abstract}

Article Information:

Date Submitted: 03/12/2019

Keywords:Burden, Diabetes, Eye diseases, Patterns, Nigeria, Southeast

\section{INTRODUCTION}

$\mathrm{D}$ iabetes mellitus (DM) is a non communicable disease with increasing prevalence in the world. DM was estimated to affect 371 million people worldwide in 2013 with about 5 million Nigerians affected ${ }^{2}$ and the projection by $\mathrm{WHO}$ is that 552 million people will be affected by 2030, with 298 million of those affected domiciled in developing countries ${ }^{3}$. The WHO estimates that Nigeria has the largest number of people living with diabetes in Africa. ${ }^{1,3}$ Uncorrected refractive errors and ocular diseases such as glaucoma, diabetic retinopathy, age-related macular degeneration and cataract are the major causes of visual impairment worldwide. ${ }^{4}$ Diabetes mellitus is a leading cause of cardiovascular diseases, end stage renal disease (ESRD), lower extremity amputation 
and adult blindness. ${ }^{5}$ It causes microvascular and macrovascular complications involving multiple systems in the body. In the eye, DM complications can involve any part of the eye from the lid to the anterior and posterior segments of the eyes. ${ }^{5}$ Diagnosis of DM is made in some persons in the Ophthalmology clinic when they present with eye complaints. Diabetic eye diseases are estimated to be present in more than a quarter of persons with type 2 diabetes and half of persons with type 1 diabetes underlining the importance of regular monitoring ${ }^{6}$

Magulike et al in their study in Enugu ${ }^{7}$ reported that out of the diabetic patients seen in the outpatient Ophthalmology clinic, $2.0 \%$ were blind, $12.8 \%$ had DM retinopathy, $22.1 \%$ had cataract and $4.7 \%$ had glaucoma while in $\mathrm{Uyo}^{8}$, it was reported that cataract $(56.4 \%)$ was the commonest DM ocular complication followed by non-proliferative diabetic retinopathy (31\%) and glaucomatous disc cupping (11.4\%). In a study in South Africa, it was reported that in the general population, cataract was the leading cause of blindness followed by uncorrected refractive error, glaucoma, DM retinopathy and ARMD ${ }^{9,10}$ In the same study, DM retinopathy was the third most common cause of blindness in persons living with diabetes after cataract and glaucoma. ${ }^{11}$ In another study, diabetic retinopathy was the leading cause of preventable blindness in working age adults and the potential risks of blindness in an individual with DM was 2.4 times higher than that of a person without diabetes. ${ }^{12,13}$

In 2010, the WHO estimated that 285 million people globally are visually impaired $-90 \%$ are said to be living in low income settings. ${ }^{14,15}$ A year before then, in 1999, the WHO had launched Vision 2020, a global plan for the elimination of avoidable blindness by $2020{ }^{9}$ With increasing prevalence of DM globally, diabetic eye diseases are increasingly becoming problems to persons living with diabetes. According to the latest report of the Vision loss Expert Group of the Global Burden of Disease study, prevalence of vision impairment and blindness caused by diabetic retinopathy increased between $1990-2015$ in developed countries. ${ }^{15}$

Because DM eye complications can lead to visual loss and blindness, it is worthwhile to define the magnitude and pattern of diabetes eye diseases. This done, one can then design an effective program for management and prevention of blindness from DM. There is a dearth of published studies on the burden and patterns of diabetes eye diseases in the commercial city of Aba, Nigeria, hence the need for this study.

\section{MATERIALS AND METHODS}

\section{Study Design and Setting}

This was a 6-year retrospective study conducted at the Ophthalmology clinic of Abia State University Teaching Hospital (ABSUTH) Aba, Nigeria between January 2013 and December 2018. The Ophthalmology clinic in ABSUTH operates two days every week in which all patients with eye complaints or referred from peripheral hospitals are attended to. The hospital (ABSUTH) is the only teaching hospital in Aba which is a commercial city in the South East region of Nigeria known for her industrial, trading, and craftwork activities.

\section{Recruitment and data collection}

The data of diabetic patients referred to or presented at the Ophthalmology clinic of ABSUTH were extracted from the Nurse's Outpatient Register and used for the study. All the patients with a diagnosis of DM (from fasting or random blood glucose of more than 7.0 or $11.1 \mathrm{mmol} / 1$ respectively) were noted and their Case notes obtained from the Medical Records office. Each of them had been examined by ophthalmologists and optometrists when they visited the clinic using Snellens chart for visual acuity, auto-refractor for refraction, tonometer for tonometry, slit-lamp for examination of the anterior segment and fundus examination using indirect ophthalmoscope and +78 dioptre lens. Data collected included their age, gender and eye findings/diagnosis which were entered into the SPSS software, version 20.0 (SPSS, Inc, Chicago IL) and analyzed. Level of statistical significance was set at $p<0.05$.

\section{RESULTS}

A total of 5280 outpatient visits to the Ophthalmology clinic of ABSUTH, Aba, South East, Nigeria was recorded within the study period of which 126 patients (2.4\%) were living with diabetes mellitus. Participants in the study were 56 (44.4\%) males and 70 (55.6\%) females, aged between 38-75 years with a mean age of $54.64 \pm 10.26$ years. Majority of the subjects $(60.3 \%)$ were middle aged, followed by the elderly people (table 1). Pattern of diabetic eye diseases over the 6year period is summarized in table 2. Cataract alone was the diagnosis in $41.3 \%$ of the participants and when cataract is considered in combination with other eye conditions such as diabetic retinopathy, ocular hypertension, retinal detachment, 
iris neovascularization and diabetic macular oedema, it accounted for $50 \%$ of the diabetes eye complications. Presbyopia (10.3\%), refractive error and presbyopia together $(10.3 \%)$, refractive error alone $(7.9 \%)$, DM retinopathy (9.5\%), ocular hypertension (7.2\%), diabetic macula oedema $(5.2 \%)$ and retinal detachment $(4 \%)$, were the other common eye diseases prevalent in the study population within the study period. None of the participants was blind and glaucoma $(0.8 \%)$ was the least common eye disease which was present. Systemic hypertension and ARMD were the commonest co morbid condition in the participants (table 3 )

Table 1 : Gender distribution of the participants stratified by age groups in ABSUTH Ophthalmology clinic, Aba

\begin{tabular}{llll}
\hline Age group & Male & Female & Total \\
20-39 years & 4 & 4 & $8(6.4 \%)$ \\
40-59 years & 32 & 44 & $76(60.3 \%)$ \\
60 years and above & 20 & 22 & $42(33.3 \%)$ \\
Total & $\mathbf{5 6}$ & $\mathbf{7 0}$ & $\mathbf{1 2 6}$ \\
\hline
\end{tabular}

Table 2 Pattern of eyẹ diseases in DM patients accessing outpatient ophthalmology care in ABSUTH, Aba

\begin{tabular}{ll}
\hline Eye diseases & Frequency (n=126) (\%) \\
\hline Presbyopia & $13(10.3)$ \\
Cataract & $52(41.3)$ \\
DM retinopathy & $10(7.9)$ \\
Glaucoma & $1(0.8)$ \\
Refractive error & $10(7.9)$ \\
Diabetic macular oedema & $4(3.2)$ \\
Iris Neovascularization & $2(1.6)$ \\
Cataract and DM retinopathy & $2(1.6)$ \\
Refractive error and presbyopia & $13(10.3)$ \\
Cataract and ocular HTN & $5(4.0)$ \\
Retinal detachment & $3(2.4)$ \\
Retinal detachment and cataract & $2(1.6)$ \\
NVG and cataract & $1(0.8)$ \\
Ocular HTN and refractory error & $2(1.6)$ \\
DME and cataract & $1(0.8)$ \\
ARMD & $3(2.4)$ \\
DME and ocular HTN & $1(0.8)$ \\
Dm retinopathy and ocular HTN & $1(0.8)$ \\
Total & $126(100)$ \\
\hline
\end{tabular}

Key $: N V G=$ Iris neovascularization, ocular HTN = ocular hypertension, $D M E=$ diabetic macular oedema, $A R M D=$ age

- related macular degeneration

Table 3: Pattern of comorbid conditions in the participants

\begin{tabular}{lll}
\hline Co-morbid conditions & Frequency & Percent \\
\hline Systemic hypertension & 5 & 4.0 \\
ARMD & 3 & 2.4 \\
Infective conjunctivitis & 4 & 3.2 \\
Nil co morbid eye or systemic disease & 114 & 90.4 \\
Total & $\mathbf{1 2 6}$ & $\mathbf{1 0 0}$ \\
\hline
\end{tabular}

Key: $A R M D=$ age related macular degeneration 


\section{DISCUSSION}

The main findings of this study included a $2.4 \%$ diabetes burden on the Outpatient Ophthalmology clinic visits of ABSUTH, Aba, South East, Nigeria. Cataract was the commonest diabetic eye complication with glaucoma being rare while systemic hypertension was the commonest co morbid condition.

These findings support internationally recommended ${ }^{16,17}$ annual routine screening of all persons living with diabetes for ocular complications which may go a long way to preventing visual loss and blindness arising from diabetes. This diabetes burden reported in the index study is in keeping with the report by Cheung et al that the potential risks of blindness in an individual with DM was 2.4 times higher than that of a person without diabetes ${ }^{11}$. The implication of this significant diabetes burden on the outpatient Ophthalmology clinic visits in ABSUTH, Aba is that the diabetes care team and the Ophthalmology unit need to cooperate more with each other aimed at preventing visual loss and blindness in persons living with diabetes.

In the index study, that cataract alone and with other eye complications constituted the commonest diabetes ocular complication is similar to the reports in Enugu ${ }^{7}, \mathrm{Uyo}^{8}$ and South Africa. ${ }^{10}$ Frequency of cataract as a DM ocular complication in the index study $(50 \%)$ was similar to the $56.4 \%$ reported in Uyo and greater than the $22.1 \%$ reported in Enugu. Reasons for the disparity in frequency of cataract as a diabetic ocular disease in Enugu, Uyo and the index study is not known but could be because of the increasing prevalence of DM over the years and changing treatment modalities bearing in mind that the Enugu report was in 2003 while the Uyo and index study were reported more than 10 years after the study in Enugu.

The high frequency of presbyopia alone or in combination with refractive error (20.6\%) was not reported in the Enugu and Uyo studies. It is not clear whether these conditions occurred as a diabetic eye complication or same as would have been found in the general population.

Diabetic retinopathy $(9.5 \%)$ in the index study is comparable to the reports in Enugu and South Africa where DM retinopathy was found to be an important sight threatening complication of DM. It is, also, comparable to the $7.4 \%$ frequency in a cross sectional study in Rivers ${ }^{18}$ State, Southsouth, Niigeria However, diabetic retinopathy in the present study is lower than the $36 \%$ and $32.6 \%$ frequency of DM retinopathy noted in other Nigerian tertiary hospital based studies in Kano ${ }^{19}$ and Ado Ekiti ${ }^{20}$ respectively. The implication of these findings is that with routine screening of persons living with DM for these eye complications, many would be saved the agony of treatable and preventable visual loss and blindness.

Diabetic macular oedema and retinal detachment are serious sight threatening conditions noted in the index study but were not reported in the Enugu and Uyo studies. Reasons why they were not reported in those studies even though their frequencies in the index study were high cannot easily be given but could be from the expertise of the manpower and or sophistication of instruments used. It is important to note that unlike in the Enugu study where two of the participants were blind, none of the participants in the index study was blind. This could, probably, be a consequence of improved diabetes education and awareness of the need for regular ophthalmic check for DM patients.

Finally, glaucoma was found in the index study to be a rare occurrence $(0.8 \%)$ in persons living with diabetes unlike the situations as reported in Enugu (4.7\%), Uyo (11.4\%) and in Souith Africa where glaucoma even came second after cataract. In South Africa, glaucoma was commoner than DM retinopathy. Explanation for this disparity is not clear. It is worthy of note that in the index study, systemic hypertension and age-related macular degeneration are significant comorbid conditions that were not documented in the Enugu, Uyo and South African studies. Both conditions and even DM increase with increasing age; therefore, one is not surprised that they are significant co-morbidity in this study. This finding is in agreement with Voleti and Hubschman ${ }^{21}$ who noted that the prevalence of vision problems is strongly associated with ageing and this compromised visual function affects individuals' ability to perform activities of daily living. Systemic hypertension is amenable to medical treatment and should be treated adequately when present.

\section{CONCLUSION}

Cataract, DM retinopathy and macular oedema with or without refractive error are common diabetic ocular complications in the commercial city of Aba, South East. Nigeria where the burden of diabetes to the outpatient Ophthalmology visits is significant. Systematic screening of DM patients has the potential to reduce the incidence of sight threatening visual impairment and blindness. Such 
programmes / measures need to be implemented in all health facilities where diabetes care is undertaken.

\section{REFERENCES}

1. King H, Aubert R, Herman WH. Global burden of Diabetes, 1995-2025, prevalence, numerical estimates and projections. Diabetes Care. 1998; 21: 1414-1431.

2. Chinenye S, Ofoegbu EN, Onyemelukwe GC, Uloko AO, Ogbera AO. editors, Epidemiology of Diabetes Mellitus. In: Clinical Practice Guidelines for Diabetes Management in Nigeria, $2^{\text {nd }}$ ed. Portharcourt: Diabetes Association of Nigeria; 2013: 2-8

3. International Diabetes Federation: IDF Diabetes Atlas. $6^{\text {th }}$ edition. Brussels, Belgium: International Diabetes Federation 2013: http//www.idf.org/diabetes atlas (accessed 6 ${ }^{\text {th }}$ May, 2015).

4. Resnikoff S, Keys TU. Future trends in global blindness. Indian J Ophthalmol. 2012;60(5):387-95.

5. Alvin CP. Diabetes Mellitus. In: Jameson JL, editor, Harrisons Endocrinology, $2^{\text {nd }}$ ed. New York McGraw Hill; 2010; 267.

6. Li, J.Q., Welchowski, T., Schmid, M. et al. Prevalence, incidence and future projection of diabetic eye disease in Europe: a systematic review and meta-analysis. Eur $J$ Epidemiol (2019). https://doi.org/10.1007/s10654-01900560-Z

7. Magulike NO, Chuka-Okosa CM, Oli JM. Diabetic eye disease in Enugu South Eastern Nigeria - A preliminary Report. Nigerian Journal of Ophthalmology. 2003; 11(1): 30-33.

8. Abraham EG, Umoh V. Occular health status of diabetes mellitus patients in Uyo, South- South Nigeria. IOSR Journal of Dental and Medical Sciences. 2013; 9(2): 24 28.

9. World Health Organization Elimination of avoidable blindness and launching of regional vision 2020. Geneva: World Health Organization; 1999 http://apps.searo.who.int/PDS_DOCS/B3557. (Accessed May 5, 2016).

10. South African Department of Health National guideline Prevention of blindness in South africa. Pretoria: $\mathrm{D}$ e p a r t m e $\mathrm{nt}$ of $\mathrm{He}$ a $1 \mathrm{th} ; 2002$. https://www.westerncape.gov.za/text/2003/blindness. (Accessed Jan 18 2014).

11. Cheung N, Mitchel P, Wong TY. Diabetic Retinopathy.
Lancet. 2010; 376: $124-136$.

12. Genz J, et al. Reduced incidence of blindness in relation to diabetes mellitus in Southern Germany? Diabet Med. 2010; $27: 1138$ - 1143)

13. World Health Organization Universal eye health: A global action plan 2014-2019. Geneva: World Health $\begin{array}{llllllllllllllllllllllllllll}\mathrm{O} & \mathrm{r} & \mathrm{g} & \mathrm{a} & \mathrm{n} & \mathrm{i} & \mathrm{z} & \mathrm{a} & \mathrm{t} & \mathrm{i} & \mathrm{o} & \mathrm{n} & ; & 2 & 0 & 1 & 3\end{array}$. https://www.who.int/blindness/AP2014_19_English. (Accessed Nov 30, 2016).

14. World Health Organization Visual impairment and blindness. Geneva: World Health Organization; no date (Accessed Nov 30, 2015).

15. Flaxman SR, Bourne RRA, Resnikoff S, Ackland P, Braithwaite T, Cicinelli MV et al. Global causes of blindness and distance vision impairment 1990 - 2020: a systematic review and metanalysis. Lancet Global Health. 2017; 5: e1221-e1234

16. Ministry of Health, Guidelines for the screening and management of Diabetic Retinopathy in Kenya; 2017. Nairobi, Kenya

17. NICE sugar study investigators. N Eng J Med. 2009. 360: 1283-129.

18. Chinenye S, Uchenna DI, Unachukwu CN. Ogbera AO and Ojule AC. The pattern of Diabetes Mellitus in Rivers State, Nigeria. Nig Endocrine Practice.2006; 87-93.

19. Lawan A, Mohammed TB. Pattern of diabetic retinopathy in Kano, Nigeria. Ann Afr Med. 2012 Apr-Jun;11(2):75-9. doi: 10.4103/1596-3519.93528.

20. Ajayi IA, Raimi TH, Omotoye OJ, Ajite KO. Ocular findings in a diabetic Retinopathy Screening clinic in South west Nigeria. Sky Journal of Medicine and Medical Sciences. 2011; Vol 4(3): 023-027.

21.Voleti VB, Hubschman JP. Age-related eye disease. Maturitas. 2013;75(1):29-33. 